\title{
Article \\ Observational Study of Hand Hygiene Compliance at a Trauma Hospital in Iraqi Kurdistan
}

\author{
Ines Moued ${ }^{1}$, Rawand M. Haweizy ${ }^{2,3}{ }^{\circledR}$, Lawand S. Miran ${ }^{4}$, Mustafa G. Mohammed ${ }^{3}$, Johan von Schreeb ${ }^{1}$ and \\ Andreas Älgå $1, *$ (1) \\ 1 Department of Global Public Health, Karolinska Institutet, 17177 Stockholm, Sweden; \\ ines.moued@hotmail.com (I.M.); johan.von.schreeb@ki.se (J.v.S.) \\ 2 College of Medicine, Hawler Medical University, Erbil 44001, Iraq; rawand_haweizy@yahoo.com \\ 3 Emergency Management Center, Erbil 21412, Iraq; mustafa_gaylan@yahoo.com \\ 4 West Erbil Emergency Hospital, Erbil 44001, Iraq; la_miran@yahoo.com \\ * Correspondence: andreas.alga@ki.se
}

Citation: Moued, I.; Haweizy, R.M.; Miran, L.S.; Mohammed, M.G.; von Schreeb, J.; Älgå, A. Observational Study of Hand Hygiene Compliance at a Trauma Hospital in Iraqi Kurdistan. J 2021, 4, 794-802. https://doi.org/10.3390/j4040054

Academic Editor: Jon Øyvind Odland

Received: 19 October 2021

Accepted: 17 November 2021

Published: 22 November 2021

Publisher's Note: MDPI stays neutral with regard to jurisdictional claims in published maps and institutional affiliations.

Copyright: (c) 2021 by the authors. Licensee MDPI, Basel, Switzerland. This article is an open access article distributed under the terms and conditions of the Creative Commons Attribution (CC BY) license (https:// creativecommons.org/licenses/by/ $4.0 /)$.

\begin{abstract}
Healthcare-associated infections, commonly caused by poor hand hygiene, represent a significant source of disease and economic burden for healthcare systems, especially those in resource-limited settings. The few existing studies on hand hygiene compliance in resource-limited hospital settings suggest that compliance is insufficient. The difference in compliance rates between units in resource-limited trauma hospitals is largely unknown. We aimed to assess hand hygiene compliance rates among healthcare workers at a trauma hospital in Iraqi Kurdistan and compare the levels of compliance between the emergency room (ER), the intensive care unit (ICU), and the acute care ward (ACW). We carried out overt observations in 2018 using the validated World Health Organization 'five moments for hand hygiene' observational tool. We observed a total of 622 hand hygiene opportunities performed by 149 healthcare workers. Hand hygiene compliance was defined as handwashing with soap and water or the use of alcohol-based hand rub, in accordance with the 'five moments for hand hygiene' concept. Overall, the hand hygiene compliance rate was found to be $6.8 \%$ (95\% confidence interval 5.0-9.1). Compliance was significantly lower in the ER (1.0\%), compared with the ICU $(8.1 \%)(p=0.0012)$, and the ACW $(11.1 \%)(p<0.0001)$. In all three units, the availability of alcohol-based hand rub and handwashing sinks was insufficient in relation to the number of patient beds. We conclude that the overall level of hand hygiene compliance was low, with the lowest level of compliance in the ER. Our findings call for improved resource allocation and strengthened hand hygiene routines. These relatively simple measures could potentially lower the incidence of healthcare-associated infections and improve the mortality and morbidity of patients in already overburdened healthcare systems.
\end{abstract}

Keywords: hand hygiene compliance; healthcare-associated infection; trauma care

\section{Introduction}

Healthcare-associated infections (HAIs) are spread by the transmission of microorganisms from a patient or a patient's surroundings to another patient, usually via equipment or via the hands of healthcare workers (HCWs) [1]. HAIs are associated with significant mortality and morbidity, and place an economic burden on healthcare systems [2]. In European high-income countries, more than 4 million patients are affected by HAIs annually, with urinary tract infections being the most frequent type of HAI, followed by lower respiratory tract infections, surgical site infections, and bloodstream infections [3,4].

HAIs are of greatest prevalence in low- and middle-income countries, in part due to the limited resources available at public hospitals, including those for hand hygiene, with surgical site infections being the most frequent type of HAIs [5,6]. Cesarean sections are among the most common operative procedures in low- and middle-income countries and are associated with maternal and neonatal mortality caused by HAIs [7]. A high prevalence 
of antimicrobial resistance adds to the severity of HAIs in resource-limited hospitals [8,9]. In addition to HAIs caused by microorganisms, viral HAIs remain a challenge to healthcare systems worldwide $[10,11]$. This significant burden has been exemplified by the ongoing COVID-19 pandemic [12].

Proper hand hygiene among HCWs is recognized by the World Health Organization (WHO) as the single most effective strategy for preventing HAIs $[13,14]$. The WHO's concept of 'five moments for hand hygiene' takes an evidence-based approach and defines five key moments at which HCWs should perform hand hygiene routines during clinical care $[14,15]$. Low hand hygiene compliance (HHC) has been proven to cause higher rates of HAIs $[1,2,16]$. Hand wash with soap and water and alcohol-based hand rub (ABHR) have proven to be effective against HAIs caused by microorganisms and viruses [17].

Still, often the importance of hand hygiene is insufficiently recognized by HCWs, and poor levels of compliance with the WHO recommendations on hand hygiene have been repeatedly documented in resource-limited hospitals $[5,18,19]$. Moreover, the implementation of hand hygiene strategies remains a challenge due to a limited access to soap and ABHR, as well as the limited provision of handwashing sinks, and hand hygiene guidelines $[20,21]$. The WHO recommends a hospital sink-to-bed ratio of at least 1:10 and an ABHR-to-bed ratio of 1:1 [22]. However, resource-limited hospitals often do not adhere to these recommendations [22]. Differences in HHC rates between the units in resourcelimited trauma hospitals are largely unknown and there is a paucity of information on the availability of hand hygiene resources at such hospital units $[5,6,16]$. Improved knowledge of HHC and the hand hygiene resources that are available is necessary to identify hospital units where there is an increased risk of the patients developing HAIs. Therefore, we aimed to assess and compare the levels of HHC in the emergency room (ER), the intensive care unit (ICU), and the acute care ward (ACW) of a resource-limited trauma hospital. In addition, we aimed to measure the ABHR-to-bed and sink-to-bed ratios in the same units.

\section{Results}

\subsection{Infrastructure}

Six handwashing sinks were available for the 56 patient beds (10.7\%; thus, a sink-tobed ratio of 1:9). Soap was provided at four of the six sinks (66.7\%). There was ABHR at two of the 56 patient beds (3.6\%; thus, an ABHR-to-bed ratio of 1:28) (Appendix A Table A1).

\subsection{Observations}

We performed six observation sessions with a mean observation time of $224 \mathrm{~min}$ (range: 147-283 $\mathrm{min}$ ); there were a total of 22.4 observation hours. Some 622 hand hygiene opportunities performed by 149 HCWs were observed. Among the 149 HCWs, 63 (42.3\%) were medical doctors, $69(46.3 \%)$ were nurses, $16(10.7 \%)$ were nursing students, and one $(0.7 \%)$ was a medical student (Table 1$)$. Since only one medical student was observed, this person was merged into the doctors' group for the purpose of the analyses.

Table 1. Observed healthcare workers at the West Emergency Hospital.

\begin{tabular}{ll}
\hline Profession & Number (\%) \\
\hline Medical doctors & $63(42.3 \%)$ \\
Medical students & $1(0.7 \%)$ \\
Nurses & $69(46.3 \%)$ \\
Nursing students & $16(10.7 \%)$ \\
Total & $\mathbf{1 4 9 ( \mathbf { 1 0 0 } \% )}$ \\
\hline
\end{tabular}

\subsection{Compliance of Units and Healthcare Workers}

The overall observed HHC rate was 6.8\% (95\% confidence interval 5.0-9.1). The HHC rate was significantly lower at the ER $(1.0 \%)$, when compared with the ICU $(8.1 \%)$ $(p=0.0012)$, and the ACW $(11.1 \%)(p<0.0001)$. No significant difference was observed 
between the ICU and the ACW. The HHC rate was significantly higher among the nursing students $(19.4 \%)$ than it was for the nurses $(5.7 \%)(p=0.0003)$, or the doctors $(4.3 \%)$ $(p<0.0001)$. No significant difference was observed between the nurses and the doctors (Table 2).

Table 2. Hand hygiene compliance of observed healthcare workers at the West Emergency Hospital.

\begin{tabular}{|c|c|c|c|}
\hline Characteristic & $\begin{array}{l}\text { Hand Hygiene } \\
\text { Opportunities, n }\end{array}$ & Hand Hygiene Actions, n & $\begin{array}{l}\text { Compliance, } \\
\%(95 \% \text { CI })\end{array}$ \\
\hline \multicolumn{4}{|l|}{ Unit } \\
\hline Emergency room & 205 & 2 & $1.0(0.7-3.9)$ \\
\hline Intensive care unit & 209 & 17 & $8.1(5.0-13.0)$ \\
\hline Acute care ward & 208 & 23 & $11.1(7.3-16.3)$ \\
\hline \multicolumn{4}{|l|}{ Professional category } \\
\hline Doctors \& medical student & 235 & 10 & $4.3(2.2-7.9)$ \\
\hline Nurses & 315 & 18 & $5.7(3.5-9.0)$ \\
\hline Nursing students & 72 & 14 & $19.4(11.4-30.8)$ \\
\hline \multicolumn{4}{|l|}{ Indication } \\
\hline Before patient contact & 148 & 1 & $0.7(0.4-4.3)$ \\
\hline Before aseptic task & 29 & 1 & $3.4(1.8-19.6)$ \\
\hline $\begin{array}{l}\text { After body fluid exposure } \\
\text { risk }\end{array}$ & 56 & 5 & $8.9(3.3-20.4)$ \\
\hline After patient contact & 165 & 12 & $7.3(4.0-12.6)$ \\
\hline $\begin{array}{l}\text { After contact with patient } \\
\text { surroundings }\end{array}$ & 224 & 23 & $10.3(6.8-15.2)$ \\
\hline Overall & 622 & 42 & $6.8(5.0-9.1)$ \\
\hline
\end{tabular}

CI, confidence interval.

\subsection{Compliance with the Five Action Indications}

Table 2 demonstrates how HHC varied according to the 'five moments for hand hygiene' tool. Levels of compliance were observed to be the lowest before patient contact. HHC was significantly higher after body fluid exposure $(p=0.0080)$, after touching a patient $(p=0.0084)$, and after contact with patient surroundings $(p=0.0005)$. The HCWs level of HHC before patient contact was not significantly different from their levels of HHC before an aseptic procedure.

\subsection{Glove Usage}

Glove usage was significantly higher in the ICU than in the ER $(p<0.0001)$, or the ACW $(p<0.0001)$. No significant difference in glove usage was observed between the ER and the ACW (Table 3).

Table 3. Glove usage of observed healthcare workers at the West Emergency Hospital.

\begin{tabular}{|c|c|c|}
\hline Characteristic & $\begin{array}{l}\text { Hand Hygiene } \\
\text { Opportunities, n }\end{array}$ & Glove Usage, n (\%) \\
\hline \multicolumn{3}{|l|}{ Unit } \\
\hline Emergency room & 205 & $59(28.8)$ \\
\hline Intensive care unit & 209 & $154(73.7)$ \\
\hline Acute care ward & 208 & $49(23.6)$ \\
\hline Overall & 622 & $262(42.1)$ \\
\hline \multicolumn{3}{|l|}{ Indication } \\
\hline Before patient contact & 148 & $79(53.4)$ \\
\hline Before aseptic task & 29 & $14(48.3)$ \\
\hline After body fluid exposure risk & 56 & $20(35.7)$ \\
\hline After patient contact & 165 & $64(38.8)$ \\
\hline $\begin{array}{l}\text { After contact with patient } \\
\text { surroundings }\end{array}$ & 224 & $85(37.9)$ \\
\hline
\end{tabular}




\section{Discussion}

We found that, overall, there was an insufficient level of compliance with the WHO's recommendations on hand hygiene, with significantly lower compliance in the ER than the ICU and the ACW. While the minimum sink-to-bed ratio was met, one third of the handwashing sinks were missing soap, and the access to ABHR was far from adequate. In the ER, ABHR was unavailable and, consequently, was not used at any point during the period of our observations. Additionally, we found that gloves were used in all three units, among which the ICU had the highest glove usage.

Previous studies have delivered similar findings on insufficient HHC and scarce availability of hand hygiene resources in resource-limited hospital settings, though previous findings have not been profoundly beneath the recommendations [19,20,23,24]. Studies from several Asian countries, including some set in resource-limited hospitals, have demonstrated HHC levels ranging from 18-46\% [21,25]. Studies conducted in India and China have suggested that, in these countries at least, $\mathrm{HHC}$ is lower in public hospitals compared to private hospitals $[19,26]$. In one study, conducted in the ICU of a public hospital in Turkey, overall HHC was found to be 13\% [23]. Differences in HHC rates between the units in resource-limited trauma hospitals are largely unknown.

In the ER and the ICU in this study, all patients were situated in one room with little space between the patients' beds. In the ACW, on the other hand, a maximum of two patients were kept in each room. The less crowded environment in the ACW led to the observer being more noticeable in the ACW than in the ER and the ICU. Furthermore, patient contact and routine procedures in the ACW were less frequent and more planned, as opposed to in the ER and the ICU. That difference in frequency and planning might have affected our results, given that a high workload, which tends to be more common in the ERs and ICUs of resource-limited hospitals, is associated with insufficient HHC; on the other hand, action planning has been reported to improve the hand hygiene behavior of HCWs $[19,27,28]$. One study, from an Indian hospital, demonstrated that hand hygiene is missed three times more often during resuscitation procedures, compared with other hand hygiene opportunities [29]. As resuscitation procedures occur more frequently in the ER and the ICU than during planned contact on the ward, hand hygiene may accordingly be missed more often in the ER.

The absence of ABHR in the ER in our study likely contributed to the significantly lower HHC that was observed in this unit. It has previously been suggested that an increase in the number of handwashing sinks, as a sole measure, does not increase HHC [30]. Considering that the use of ABHR takes less time than handwashing, increased availability of ABHR has been proven to be more effective in improving HHC in hospitals than adding extra sinks $[29,31]$. In addition, ABHR has been proven to more greatly reduce bacterial contamination compared to handwashing [32]. Interestingly, we found that visitors to the ICU were required to wear gloves before they could have any patient contact, while in the $\mathrm{ER}$ and the ACW there was no such requirement. The requirement to wear gloves is likely reflected in our results, demonstrating a higher glove usage in the ICU compared with the ER and the ACW. This practice in the ICU might have been a counterproductive measure, given that glove usage tends to decrease the HHC $[23,33]$. While ABHR is known to reduce bacterial and viral contamination, studies have suggested that single use of ABHR might be less effective against certain respiratory viruses compared with hand washing with soap and water, with the conclusion that ABHR should be combined with additional hygienic measures to reduce the rates of viral respiratory HAIs [34,35].

The findings of this study should be considered in the context of a number of limitations. First, observations were carried out during a limited time period, which might have resulted in a false low level of HHC observed [36]. To increase the statistical power, we observed over 200 hand hygiene opportunities per unit, in accordance with recommendations of the WHO [15]. Second, the study was performed at a single hospital, which affects the generalizability of our findings. Third, all observations were conducted by one researcher with consistency in mind, though this may have introduced researcher bias. To 
reduce this risk, we conducted a pilot study in the same hospital in which the observer was supervised by experienced researchers. Fourth, the observations in the ACW may have been more greatly subject to the Hawthorne effect than those in the ER and the ICU due to the observer being more noticeable in the less crowded and less busy work environment. The Hawthorne effect can be described as a type of reaction where individuals alter their behavior in response to their awareness of being observed. This effect may introduce observation bias as it may increase HCWs' frequency of hand hygiene actions during the period in which they are under overt observations [37].

Keeping these limitations in mind, we have demonstrated the utility of the WHO's concept of 'five moments for hand hygiene' for assessing and comparing the levels of $\mathrm{HHC}$ at different units of a resource-limited trauma hospital. Our results indicate that the availability and accessibility of ABHR must be ensured for hand hygiene routines in this setting to be strengthened. Furthermore, attention should be paid to hand hygiene awareness and education among HCWs [38]. We recommend that these interventions are based on established documents, such as the WHO's 'Multimodal Strategy for Hand Hygiene Improvement', which specifies different types of interventions at local and national levels [22]. Key interventions for raising the level of HHC in resource-limited hospital settings include education, training, evaluation, and feedback [20,21]. Hopefully, the results of our study will be prove to be valuable for the development and customization of future research on interventions that are aimed at improving HHC in settings of resource-limited trauma care.

\section{Materials and Methods}

\subsection{Study Setting}

Iraq is a southwest Asian, upper-middle-income country [39]. Over the last three decades, continuous armed conflicts have disrupted the Iraqi healthcare system and impoverished the public hospitals [40]. During times of armed conflict, the healthcare services of the affected areas are overburdened and, thus, can be considered to be resource-limited. We conducted our study at the West Erbil Emergency Hospital in Erbil, within the Kurdistan region of Iraq. This is a public emergency hospital that provides acute trauma care and surgery for the general civilian population. To our knowledge, no national or regional policy exists for the surveillance of hospitals' hand hygiene in Iraq.

\subsection{Study Design and Participants}

This is an observational study, in which we observed nurses, student nurses, doctors, and medical students. The study was based on the WHO's concept of 'five moments for hand hygiene', which defines when and how HCWs should perform hand hygiene routine during the course of clinical care [5]. We did not offer the HCWs any training in the WHO's concept prior to our observations.

\subsection{Data Collection}

We collected and recorded the data using a validated WHO hand hygiene observation tool [41]. All observations were carried out by one observer (I.M.). The first author performed a pilot test, followed by methodological discussions within the research group. The pilot test is not included in the results. Subsequently, the first author collected the data for the study over four days in July 2018. The observations were overt and the HCWs were informed about the study by the observer beforehand. When approached with questions by the hospital's staff, the observer disclosed information about the study without revealing any results.

The observer was present in one unit at a time and moved between the rooms in each unit. In all three units, the observer was positioned discretely so as not to disturb the staff's workflow. Observations were conducted based upon five hand hygiene action indications: before patient contact, before aseptic task, after body fluid exposure risk, after patient contact, and after contact with patient surroundings. Each patient was considered a unique 
observation field, meaning that when an HCW moved from one patient to another, a new observation field was created and the number of observed hand hygiene opportunities was increased by one. Similarly, if the HCW returned to a patient after terminating the previous contact, a new observation field was created and the number of observed hand hygiene opportunities was again increased by one. The observations were recorded per opportunity, meaning that one observation was considered one of the five moments in which hand hygiene action was indicated. A compliant action was defined as the presence of hand hygiene action while a non-compliant action was defined as the absence of hand hygiene action. A maximum of three HCWs were observed simultaneously and each observation lasted for a maximum of $30 \mathrm{~min}$. The selection of the observed HCWs was based on their patient contact debut within the observer's field of view, i.e., the first HCWs who were seen initiating patient contact were first selected. The observer completed a minimum of 200 observations in each unit, after which the observer moved to the next unit.

\subsubsection{Emergency Room}

The ER consisted of three separate rooms: two large rooms with ten patient beds each and one small consultation room with one patient bed. There was one separate entrance to each room. The observer's view of all the 21 beds was usually unobstructed, but some beds and their close surroundings were at times covered with curtains. One handwashing sink was located by the entrance in each room.

\subsubsection{Intensive Care Unit}

In the ICU, there were two larger adjacent rooms. One room was specifically intended for respiratory care and, at the time of the observations, patients were only being treated in the respiratory care room. There was one entrance to the respiratory care room, and there was one handwashing sink and one ABHR dispenser located by the entrance. The observer had an unobstructed view of all six beds in the room.

\subsubsection{Acute Care Ward}

The ACW consisted of an orthopedic trauma unit and a neurosurgery unit. The orthopedic trauma unit was comprised of two hallways of patient rooms, including one staff room in each hallway. There were two separate entrances to the orthopaedic trauma unit, one located in each hallway. The staff rooms were the first rooms to the left of each entrance. One of the staff rooms had one handwashing sink and one ABHR dispenser while the other staff room had one handwashing sink and no ABHR dispenser. The neurosurgery unit consisted of one large room with a total of seven beds. There was one entrance to the neurosurgery unit and one handwashing sink was located close to the entrance. The observer had an unobstructed view of all 29 beds.

\subsection{Statistical Analysis}

We calculated power based on the detection of a 15\% difference between the HCWs' HHC in the ER, the ICU, and the ACW. Based on previously published literature, we expected the HHC rate to be $20 \%$ at the ACW [21,42]. On the basis of a power of $90 \%$ and a significance level of $5 \%$, we calculated that a minimum sample size of 184 hand hygiene opportunities per unit would be required to detect a significant difference in HHC. To be able to adjust for unforeseen events, we aimed to obtain 200 observations per unit.

Data obtained from the observations were recorded on a paper observation form and then entered into an Excel ${ }^{\circledR}$ spreadsheet (Microsoft, Redmond, Washington, USA). Chisquare and Fisher's exact tests were used to assess statistical significance. Where statistical significance was found, a test of equal proportions was performed. Mean values and proportions with $95 \%$ confidence intervals were computed. $p$-values $<0.05$ were considered to be significant. We used $R$ version 3.5.0 software for all statistical analyses [43]. 


\section{Conclusions}

In a resource-limited trauma hospital setting, compliance with the WHO's recommendations on hand hygiene was found to be insufficient, and significantly lower in the ER when compared with the ICU and the ACW. The hand hygiene resources in all observed units were scarce and did not meet the WHO's recommendations. Given the known link between low HHC and a higher incidence of HAIs, relatively simple measures to increase HHC could potentially improve the mortality and morbidity of patients in already overburdened healthcare systems. We propose for future studies to focus on interventions to improve compliance. On a larger scale, the development and implementation of national policies and surveillance strategies to monitor and evaluate hand hygiene and other infection control measures in hospitals might reduce HAIs and its consequences.

Author Contributions: Conceptualization, A.Ä. and J.v.S.; methodology, A.Ä.; data collection, I.M.; formal analysis, A.Ä.; resources, R.M.H., L.S.M. and M.G.M.; data curation, A.Ä.; writing—original draft preparation, I.M.; writing—review and editing, A.̈̈., J.v.S., R.M.H., L.S.M. and M.G.M.; supervision, A. Ä.; project administration, A.Ä.; funding acquisition, J.v.S. All authors have read and agreed to the published version of the manuscript.

Funding: This research was funded by grants provided by the Swedish National Board of Health and Welfare.

Institutional Review Board Statement: The study was conducted according to the guidelines of the Declaration of Helsinki, and was approved by the Research Ethics Committee of Hawler Medical University in Erbil, Iraq (7:6 26 June 2018) before study initiation.

Informed Consent Statement: No identifying information about the HCWs was recorded; consequently, the need for individual consent to participate was formally waived by the ethics committee.

Data Availability Statement: Data will be made available on reasonable request.

Acknowledgments: We would like to thank all the participants of the study.

Conflicts of Interest: The authors declare no conflict of interest. The funders had no role in the design of the study; in the collection, analyses, or interpretation of data; in the writing of the manuscript, or in the decision to publish the results.

\section{Appendix A}

Table A1. Infrastructure in units of the West Erbil Emergency Hospital.

\begin{tabular}{llll}
\hline Characteristic & Beds, $\mathbf{n}$ & Sinks, $\mathbf{n}$ & ABHR, $\mathbf{n}$ \\
\hline Unit & & & \\
Emergency room & 21 & 2 & 0 \\
Intensive care unit & 6 & 1 & 1 \\
Acute care ward & 29 & 3 & 1 \\
\hline
\end{tabular}

ABHR, alcohol-based hand rub.

\section{References}

1. Girard, R.; Perraud, M.; Prüss, A.; Savey, A.; Tikhomirov, E.; Thuriaux, M.; Vanhem, P. Prevention of Hospital-Acquired Infections: A Practical Guide, 2nd ed.; World Health Organization: Geneva, Switzerland, 2002. Available online: https://apps.who.int/iris/ bitstream/handle/10665/67350/WHO_CDS_CSR_EPH_2002.12.pdf (accessed on 18 October 2021).

2. Salama, M.F.; Jamal, W.Y.; Mousa, H.A.; Al-AbdulGhani, K.A.; Rotimi, V.O. The effect of hand hygiene compliance on hospitalacquired infections in an ICU setting in a Kuwaiti teaching hospital. J. Infect. Public Health 2013, 6, 27-34. [CrossRef]

3. Klevens, R.M.; Edwards, J.R.; Richards, C.L., Jr.; Horan, T.C.; Gaynes, R.P.; Pollock, D.A.; Cardo, D.M. Estimating health care-associated infections and deaths in U.S. hospitals, 2002. Public Health Rep. 2007, 122, 160-166. [CrossRef]

4. European Centre for Disease Prevention and Control. Annual Epidemiological Report on Communicable Diseases in Europe 2008; European Centre for Disease Prevention and Control: Stockholm, Sweden, 2008.

5. Loftus, M.J.; Guitart, C.; Tartari, E.; Stewardson, A.J.; Amer, F.; Bellissimo-Rodrigues, F.; Lee, Y.F.; Mehtar, S.; Sithole, B.L.; Pittet, D. Hand hygiene in low- and middle-income countries. Int. J. Infect. Dis. 2019, 86, 25-30. [CrossRef] 
6. Allegranzi, B.; Nejad, S.B.; Combescure, C.; Graafmans, W.; Attar, H.; Donaldson, L.; Pittet, D. Burden of endemic health-careassociated infection in developing countries: Systematic review and meta-analysis. Lancet 2011, 377, 228-241. [CrossRef]

7. Di Gennaro, F.; Marotta, C.; Pisani, L.; Veronese, N.; Pisani, V.; Lippolis, V.; Pellizer, G.; Pizzol, D.; Tognon, F.; Bavaro, D.F.; et al. Maternal caesarean section infection (MACSI) in Sierra Leone: A case-control study. Epidemiol. Infect. 2020, 148, E40. [CrossRef]

8. Kanapathipillai, R.; Malou, N.; Baldwin, K.; Marty, P.; Rodaix, C.; Mills, C.; Herard, P.; Saim, M. Antibiotic resistance in Palestine: An emerging part of a larger crisis. BMJ 2018, 363, k4273. [CrossRef]

9. Älgå, A.; Wong, S.; Shoaib, M.; Lundgren, K.; Giske, C.G.; Von Schreeb, J.; Malmstedt, J. Infection with high proportion of multidrug-resistant bacteria in conflict-related injuries is associated with poor outcomes and excess resource consumption: A cohort study of Syrian patients treated in Jordan. BMC Infect. Dis. 2018, 18, 233. [CrossRef]

10. Godoy, P.; Torner, N.; Soldevila, N.; Rius, C.; Jane, M.; Martínez, A.; Caylà, J.; Domínguez, A.; Alsedà, M. Hospital-acquired influenza infections detected by a surveillance system over six seasons, from 2010/2011 to 2015/2016. BMC Infect. Dis. 2020, 20, 1-7. [CrossRef]

11. French, C.E.; McMenzie, B.C.; Coope, C.; Rajanajdu, S.; Paranthaman, K.; Pebody, R.; Nguyen-Van-Tam, J.S.; Noso-RSV Study Group; Higgins, J.P.T.; Beck, C.R. Risk of nosocomial respiratory syncytial virus infection and effectiveness of control measures to prevent transmission events: A systematic review. Influenza Other Respir. Viruses 2016, 10, 268-290. [CrossRef]

12. Abbas, M.; Nunes, T.R.; Martischang, R.; Zingg, W.; Iten, A.; Pittet, D.; Harbarth, S. Nosocomial transmission and outbreaks of coronavirus disease 2019: The need to protect both patients and healthcare workers. Antimicrob. Resist. Infect. Control 2021, 10, 1-13. [CrossRef]

13. World Health Organization. WHO Guidelines on Hand Hygiene in Health Care: First Global Patient Safety Challenge Clean Care Is Safer Care; World Health Organization: Geneva, Switzerland, 2009. [CrossRef]

14. World Health Organization. Evidence for Hand Hygiene Guidelines; World Health Organization: Geneva, Switzerland, 2011. [CrossRef]

15. World Health Organization. Hand Hygiene Technical Reference Manual; World Health Organization: Geneva, Switzerland, 2009.

16. World Health Organization. Report on the Burden of Endemic Health Care-Associated Infection Worldwide; World Health Organization: Geneva, Switzerland, 2011.

17. Larson, E.L.; Cohen, B.; Baxter, K.A. Analysis of alcohol-based hand sanitizer delivery systems: Efficacy of foam, gel, and wipes against influenza A (H1N1) virus on hands. Am. J. Infect. Control 2012, 40, 806-809. [CrossRef]

18. Älgå, A.; Herzog, K.K.; Alrawashdeh, M.; Wong, S.; Khankeh, H.; Lundborg, C.S. Perceptions of Healthcare-Associated Infection and Antibiotic Resistance among Physicians Treating Syrian Patients with War-Related Injuries. Int. J. Environ. Res. Public Health 2018, 15, 2709. [CrossRef]

19. Tyagi, M.; Hanson, C.; Schellenberg, J.; Chamarty, S.; Singh, S. Hand hygiene in hospitals: An observational study in hospitals from two southern states of India. BMC Public Health 2018, 18, 1299. [CrossRef]

20. Pfäfflin, F.; Tufa, T.B.; Getachew, M.; Nigussie, T.; Schönfeld, A.; Häussinger, D.; Feldt, T.; Schmidt, N. Implementation of the WHO multimodal Hand Hygiene Improvement Strategy in a University Hospital in Central Ethiopia. Antimicrob. Resist. Infect. Control 2017, 6, 3. [CrossRef]

21. Allegranzi, B.; Gayet-Ageron, A.; Damani, N.; Bengaly, L.; McLaws, M.-L.; Moro, M.L.; Memish, Z.; Urroz, O.; Richet, H.; Storr, J.; et al. Global implementation of WHO's multimodal strategy for improvement of hand hygiene: A quasi-experimental study. Lancet Infect. Dis. 2013, 13, 843-851. [CrossRef]

22. World Health Organisation. Guide to Implementation Multimodal Hand Hygiene Improvement Strategy; World Health Organization: Geneva, Switzerland, 2009.

23. Karabey, S.; Ay, P.; Derbentli, Ş.; Nakipoğlu, Y.; Esen, F. Handwashing frequencies in an intensive care unit. J. Hosp. Infect. 2002, 50, 36-41. [CrossRef]

24. Alp, E.; Leblebicioglu, H.; Doganay, M.; Voss, A. Infection control practice in countries with limited resources. Ann. Clin. Microbiol. Antimicrob. 2011, 10, 36. [CrossRef]

25. Han, K.; Dou, F.M.; Zhang, L.J.; Zhu, B.P. Compliance on hand-hygiene among healthcare providers working at secondary and tertiary general hospitals in Chengdu. Zhonghua Liu Xing Bing Xue Za Zhi 2011, 32, 1139-1142.

26. Ye, L.-P.; Zhang, X.-P.; Lai, X.-Q. Does hospital ownership influence hand hygiene compliance? Curr. Med. Sci. 2017, 37, 787-794. [CrossRef]

27. Scheithauer, S.; Batzer, B.; Dangel, M.; Passweg, J.; Widmer, A. Workload even affects hand hygiene in a highly trained and well-staffed setting: A prospective 365/7/24 observational study. J. Hosp. Infect. 2017, 97, 11-16. [CrossRef]

28. Erasmus, V.; Kuperus, M.; Richardus, J.; Vos, M.; Oenema, A.; van Beeck, E. Improving hand hygiene behaviour of nurses using action planning: A pilot study in the intensive care unit and surgical ward. J. Hosp. Infect. 2010, 76, 161-164. [CrossRef]

29. Biswas, A.; Bhattacharya, S.D.; Singh, A.K.; Saha, M. Addressing Hand Hygiene Compliance in a Low-Resource Neonatal Intensive Care Unit: A Quality Improvement Project. J. Pediatr. Infect. Dis. Soc. 2018, 8, 408-413. [CrossRef] [PubMed]

30. Lankford, M.G.; Zembower, T.R.; Trick, W.; Hacek, D.M.; Noskin, G.A.; Peterson, L.R. Influence of Role Models and Hospital Design on the Hand Hygiene of Health-Care Workers. Emerg. Infect. Dis. 2003, 9, 217-223. [CrossRef] [PubMed]

31. Maury, E.; Alzieu, M.; Baudel, J.L.; Haram, N.; Barbut, F.; Guidet, B.; Offenstadt, G. Availability of an Alcohol Solution Can Improve Hand Disinfection Compliance in an Intensive Care Unit. Am. J. Respir. Crit. Care Med. 2000, 162, 324-327. [CrossRef] 
32. Karabay, O.; Sencan, I.; Sahin, I.; Alpteker, H.; Ozcan, A.; Oksuz, S. Compliance and Efficacy of Hand Rubbing during In-Hospital Practice. Med. Princ. Pr. 2005, 14, 313-317. [CrossRef] [PubMed]

33. Fuller, C.; Savage, J.; Besser, S.J.; Hayward, A.; Cookson, B.; Cooper, B.; Stone, S. "The Dirty Hand in the Latex Glove": A Study of Hand Hygiene Compliance When Gloves Are Worn. Infect. Control Hosp. Epidemiol. 2011, 32, 1194-1199. [CrossRef]

34. Savolainen-Kopra, C.; Korpela, T.; Simonen-Tikka, M.-L.; Amiryousefi, A.; Ziegler, T.; Roivainen, M.; Hovi, T. Single treatment with ethanol hand rub is ineffective against human rhinovirus-hand washing with soap and water removes the virus efficiently. $J$. Med. Virol. 2012, 84, 543-547. [CrossRef]

35. Tuladhar, E.; Hazeleger, W.; Koopmans, M.; Zwietering, M.; Duizer, E.; Beumer, R. Reducing viral contamination from finger pads: Handwashing is more effective than alcohol-based hand disinfectants. J. Hosp. Infect. 2015, 90, 226-234. [CrossRef]

36. Werzen, A.; Thom, K.A.; Robinson, G.L.; Li, S.; Rock, C.; Herwaldt, L.A.; Diekema, D.J.; Reisinger, H.; Perencevich, E. Comparing brief, covert, directly observed hand hygiene compliance monitoring to standard methods: A multicenter cohort study. Am. J. Infect. Control 2019, 47, 346-348. [CrossRef]

37. Gould, D.; Creedon, S.; Jeanes, A.; Drey, N.; Chudleigh, J.; Moralejo, D. Impact of observing hand hygiene in practice and research: A methodological reconsideration. J. Hosp. Infect. 2017, 95, 169-174. [CrossRef]

38. Di Gennaro, F.; Marotta, C.; Amicone, M.; Bavaro, D.; Bernaudo, F.; Frisicale, E.; Kurotschka, P.K.; Mazzari, A.; Veronese, N.; Murri, R.; et al. Italian young doctors' knowledge, attitudes and practices on antibiotic use and resistance: A national cross-sectional survey. J. Glob. Antimicrob. Resist. 2020, 23, 167-173. [CrossRef]

39. World Bank Group. World Bank Country and Lending Groups. Country Classification. 2020. Available online: http://data. worldbank.org/about/country-classifications (accessed on 13 October 2020).

40. Lafta, R.K.; Al-Nuaimi, M.A. War or health: A four-decade armed conflict in Iraq. Med. Confl. Surviv. 2019, 35, 209-226. [CrossRef] [PubMed]

41. Sax, H.; Allegranzi, B.; Uçkay, I.; Larson, E.; Boyce, J.; Pittet, D. 'My five moments for hand hygiene': A user-centred design approach to understand, train, monitor and report hand hygiene. J. Hosp. Infect. 2007, 67, 9-21. [CrossRef] [PubMed]

42. Kolola, T.; Gezahegn, T. A twenty-four-hour observational study of hand hygiene compliance among health-care workers in Debre Berhan referral hospital, Ethiopia. Antimicrob Resist. Infect Control 2017, 6, 109. [CrossRef] [PubMed]

43. R Core Team. R: A Language and Environment for Statistical Computing; R Core Team: Vienna, Austria, 2013. Available online: http:/ / www.R-project.org/ (accessed on 13 October 2020). 